\title{
THE ROLE OF BIRTH ORDER IN SUBSTANCE RELATED DISORDERS
}

\section{Assumptor Mukangi}

\begin{abstract}
This study was guided by two objectives. The first objective was to investigate which of the ordinal birth orders (one’s chronological position with in their family of origin) was over represented within patients receiving treatment for addiction at a drugs rehabilitation centre. The second objective was to investigate whether psychological birth order (a person's perception of their ordinal birth order) was more prevalent in relation to substance related disorders. 28 male participants admitted in a rehabilitation centre were recruited for the study. Their age ranged from 18-50 years of age. The Psychological Birth Order Inventory (PBOI) by Campbell, White \& Stewart (1991) was used to collect information concerning the participant’s psychological birth order whilst Eckstein’s 1977 ordinal birth order assessment question was used to derive information concerning the participants' ordinal position. In reference to the first objective, it was found that the youngest child was more likely to have a substance related disorder 33.3\%, followed by the first and middle child who were just as likely to develop the disorder $28.6 \%$ and lastly, an only child with a frequency of $7.6 \%$. In the second objective, it was found that majority of the participants rated themselves as psychological first borns with a frequency score of $51.9 \%$.This was followed by ratings of the psychological middle child $22.2 \%$ and the psychological only (11.1\%) The interpretations and implications of the results have been discussed.

\section{Introduction}


The study of birth order in substance related disorders is crucial. First, past research in this area was short-lived creating the need to revive it. Second, literature suggests that very few studies investigated the phenomenon making it difficult to conclude whether a birth order effect exists (Weeks \& Newlon 1984; Lerner \& Linder 1975; Smart 1963;

Schachter 1959). Third, psychological birth order has often been implicated as being more important than ordinal birth order when it comes to the effects it has on a person's lifestyle (Adler 1931). Despite this, only one study has investigated psychological birth order (Smart 1963) creating the need for further investigation.

\section{Literature review}

The area of birth order has evoked a lot of attention and a wealth of research since its first discovery in the social science field (Hartshorne, Salem-Hartshorne \& Hartshorne, 2009). Research in this area has involved the assessment of personality variables, achievement in various subjects at school and particularly intellectual ability which are the most common areas researched (Sigelman \& Rider 2008). The notion of sibling rivalry has also been intriguing and has attracted just as much attention from as early as in the Biblical era of Cain and Abel (Sulloway, 2001). Having said this, it is crucial to note that research on birth order has still not been exhausted. This is particularly the case when it comes to the role played by ordinal and psychological birth order when it comes to romantic relationships and substance related disorders. Therefore, the main objective of this study was to conduct a descriptive study to assess the role played by both ordinal and psychological birth order in substance related disorders.

The term ordinal birth order has often been used to mean the chronological order an individual falls in relation to their siblings (Adler, 1931). On the contrary, psychological 
birth order has been defined as a person's perception of their chronological position within their family of origin (Adler, 1931; Campbell, White \& Stewart, 1991). Each of the proposed birth orders (oldest, middle, youngest and only) have their distinctive personality traits which determine to a large extent the future of the individual (Campbell, et al., 1991).

In terms of the personality traits, first borns tend to have higher academic achievement and Intellectual Quotient as compared to the rest of the siblings (Zajonc, 2001; Zajonc \& Mullally, 1997; Philips \& Philips, 1994). The first born child is also the centre of attention in the family before a new sibling is incorporated into the family (Adler, 1931). It has often been suggested by Evolutionary Psychologists and Anthropologists that since a first born is 'an only child' before another sibling is born parents heavily invest in their first born child (Dunbar \& Barrett, 2007). This is because the child is looked upon as one who will carry on their family genes to the next generation; and hence, the child is treated is such a way as to ensure that the child survives long enough to reproduce future generations (Dunbar, et al., 2007).

The middleborn has often been described as 'feeling squeezed out' since they can never get the full attention as is the case with the first and last born (Craighead \& Nameroff, 2002). As a result, these middle borns often feel like they are in a race with the first born so as to take over the privileged position of their older sibling whilst still staying ahead of the youngest child (Kalkan, 2008; Adler, 1931). The middle child has also been referred to as the black sheep of the family and can go to great lengths to receive the attention 
they feel they were deprived by doing things such as joining rebellious social groups (Rickert, 2002). Research on birth order has often implicated the middleborn as being over represented in delinquent populations when compared to their older and middle child counterparts (Sutherland, Cressey \& Luckenbill, 1992). This over representation has been deemed to take place as a result of the middle child not ever receiving as much attention as the first and last child (Sutherland et al., 1992). It should be noted that the middle child syndrome can lead the individual to either end up as philanthropist or, the opposite (Rickert 2002). And particularly, the middle child has been implicated in helping others get justice possibly because they felt that there was no justice whilst growing up in the family of origin (Stewart 2004; Ashby, LoCicero \& Kenny 2003). It should also be noted that many variations of the middle born exist, i.e. in a family of four children; there exists a first child, a last child whilst the two in the middle are considered as middle children. In other cases where the family size is large, several children categorized as first, middle and lastborns.

It has often been stated that last borns also have a special place within the family in much the same way as the first born (Kalkan, 2008). The last born child has been characterized as being charming, spoilt, and social and is often babied (Kalkan, 2008; Stewart \& Campbell, 1998; Sullivan \& Schwebel, 1996). On the other hand, only children tend to be overprotected by their parents (Stewart et al., 1998; Gfroerer, Gfroerer, Curlette, White \& Kern, 2003). As is the case with the first borns, 'onlies' are the centre of attention and often receive a lot of parental pressure (Stewart et al., 1998; Gfroerer et al., 1998). As a result, 'onlies' and first borns may encounter severe emotional and psychological 
problems if they are not able to cope with parental pressures. It is therefore likely that these two birth orders may be implicated when it comes to the clinical population and particularly, in substance related disorders.

When it comes to the role played by one's ordinal birth order, few studies have looked at the of birth order in substance related disorders. This has also been the case when it comes to the role played by an individual's psychological birth order. According to Smart (1963), it is expected that last borns should be over represented amongst people with substance related disorders and particularly, amongst alcoholics. This is because previous research has often suggested that later borns and people from large families tend to respond in a different way when faced by an anxiety evoking situation. Studies have particularly reported that these later borns tend to respond to such situations by becoming more anxious (Smart, 1963; Schachter, 1959). Furthermore, evidence seems to suggest that last borns tend to be rebellious by engaging in activities such as dangerous sports to counteract the effect of being dominated by their older siblings (Rickert, 2002). Therefore, since addiction is about people gaining control of their lives by using mood altering substance(s) (Doweiko, 2008) it is possible that over representation of last borns in substance related disorders may be a coping mechanism for regaining control in their lives. If this is the case, then it is anticipated that later borns will be over represented in the current study.

In yet another study investigating the role of birth order and addiction; (Lerner \& Linder, 1975) used heroin addicts involved in polydrug use. The results of the study were 
contradictory to those of (Smart, 1963). In this study, polydrug abuse seemed to be more prevalent amongst only children.

The role of psychological birth order in addiction has also been ignored. In a study by (Weeks \& Newlon, 1984), it was discovered that participants who described themselves as psychological first borns formed majority of the population in the sample. In the second part of the research, the participants were given the definition of psychological birth order and surprisingly, most of the participants rated themselves as psychological middle borns. It is not known why participants rated themselves as psychological middle borns however, it should be noted that one's phenomenological perspective had a lot to do with the results obtained.

Since previous research in this area has been inconclusive, it is expected that either first, last or only children will be over represented in this study. It is for this reason that this research aims to fill this gap. With the above information, it is anticipated that participants who are last borns in their ordinal position will be over represented in the sample. When it comes to psychological birth order, is likely that psychological middle borns are likely to form majority of the sampled population due to the notion of the middle child syndrome. 


\section{METHOD}

\section{PARTICIPANTS}

The study included 28 participants from one of the private rehabilitation centers in Nairobi, Kenya. All the participants were male and their age ranged from 18 to above 50 years of age. The mean age was 31-40 category and the $(\mathrm{SD}=0.82)$.

\section{INSTRUMENTS}

The Psychological Birth Order Inventory (PBOI) by Campbell, White \& Stewart (1991) was used to collect information concerning the participant's psychological birth order. The instrument focuses on a person's experience within their family of origin. The PBOI has remarkable validity and reliability scores. The inventors of the PBOI have reported the alpha scores for internal reliability for men as 0.61 for the psychological first child; 0.77 for the psychological middle born; 0.55 for the youngest child and; 0.63 for an only male child (White et al., 1991; Ashby, LoCicero \& Kenny, 2003).

In assessing the ordinal birth order, Eckstein's (1977) birth order assessment was used. This entails asking the participants only one question in order to establish their ordinal birth order. Several choices are offered for participants to select from. These range from first, middle, only, youngest and other. 


\section{FINDINGS}

Since the aim of the research was to assess whether particular ordinal and psychological birth orders were more prevalent than others when it comes to substance related disorders. Descriptive statistics were used to investigate the objectives of the study.

Table 1: Descriptive Statistics for Ordinal and Psychological Birth Orders

\begin{tabular}{|l|l|l|l|}
\hline & N. & Mean. & SD. \\
\hline Ordinal Birth Order. & 27 & 2.185 & 0.962 \\
\hline Psychological Birth Order. & 27 & 2.148 & 1.537 \\
\hline
\end{tabular}

In the above table, the means and standard deviation for the participants have been presented. From the above results, it appears that the scores were closely distributed around the mean with less dispersion and variation as suggested by the low scores on the standard deviations.

Figure 1: A Bar graph presenting frequencies for Ordinal Birth Order

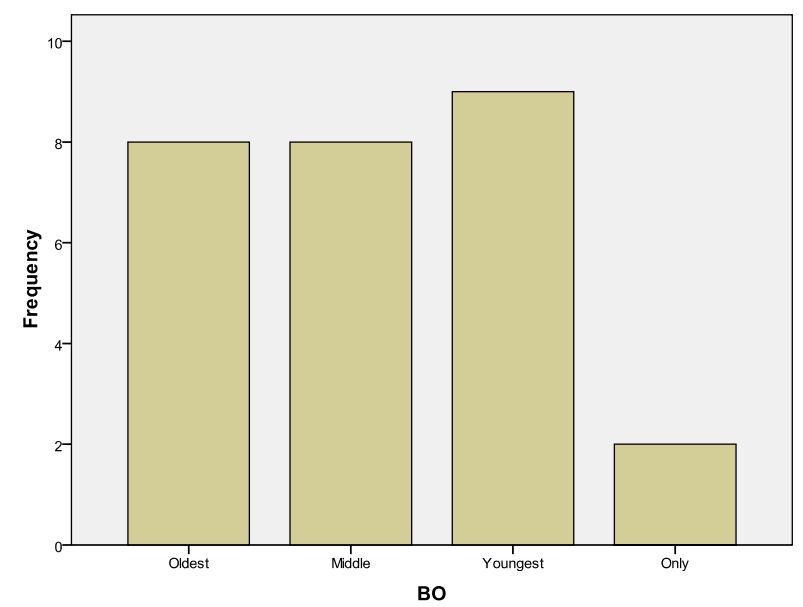


The above bar graph shows the frequencies of the participant's ordinal positions. From the graph, the youngest child was over represented in the sample since 9 (33.3\%) described themselves as youngest. This was followed by the first and middle birth orders which had an equal number of participants 8 (28.6\%). The frequency for the 'only' child was remarkably low with only 2 (7.4\%) participants.

\section{Figure 2: A Bar graph illustrating frequencies of the Psychological Birth Orders}

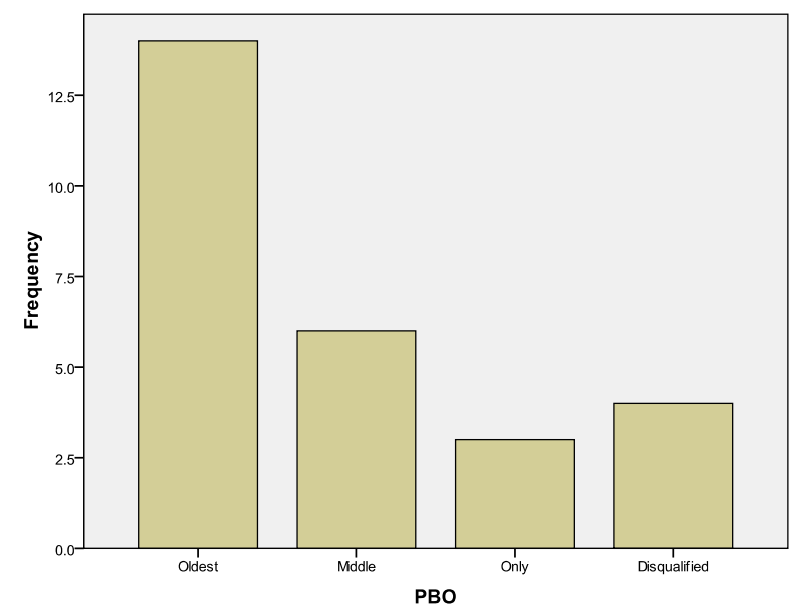

The above graph illustrates the frequencies of the various psychological birth orders. From the graph, it is clear that majority of the participants rated themselves as psychological first borns 14 (51.9\%). This was followed by ratings of the psychological middle child 6 (22.2\%); psychological only 3 (11.1\%) and finally, a group of participants who were disqualified for psychological birth order assessment 4 (14.8\%) because they had an equal number of scores for two or more psychological birth orders. 


\section{DISCUSSION}

The aim of this study was two fold. Firstly, the study aimed at investigating which ordinal position is over represented when it comes to developing a substance related disorder. A second aim of the study was to assess whether the notion of psychological birth order is applicable when it comes to addiction.

From the descriptive statistics noted above, it was evident that most of the population sampled was characterized by participants who were youngest children from their families of origin. This means that amongst the Kenyan population, it is the youngest child who is more likely to develop a substance related disorder. Several reasons could account for these results firstly, since the youngest child has a special position in much the same way as the first child, they are likely to experience an easy life whilst all their older siblings take care of them. It is therefore possible that once these youngest children grow up, they are easily overwhelmed with life situations outside the home environment; they are more likely to opt for substances as a way of coping with the world around them. The results also support those of Smart (1963) and Schachter (1959) which stated that the youngest child is more likely to become an addict and mainly because they tend to react to anxiety evoking situations by becoming more anxious. Therefore, this means that as opposed to developing strategies that relieve this anxiety, the youngest child is more inclined to use substances as a way of escaping such situations. 
Secondly, it is also possible that the youngest child is more likely to become addicted to substances since the world out there does not treat them in the same way as they were used to being treated in their family of origin causing more discord within the individual which then increases their chance of becoming addicted to substances as they seek solace in drugs. Since addiction is about regaining control that one feels they have lost, it is possible that the youngest child feels like they have to take control of their lives and rather than being assertive, they choose to become addicts as Choice theorists would put it, (Sharf 2008).

When it comes to psychological birth order, most of the participants rated themselves as psychological first borns. It is not clear why most participants rated themselves as psychological firsts though this provides more evidence suggesting that indeed psychological and ordinal birth orders are extremely different constructs. The results implicating the psychologically oldest child can child can mean several things. Firstly, it is possible that these participants were in deed treated as psychological first borns since statements relating to psychological firsts cite being a people pleaser, wanting to satisfy parents and always wanting to do things right as some of the major roles that distinguish the psychological first from the other birth orders. These 'first born related pressures' can force an individual into becoming a psychologically first and treated as such regardless of how much they try to retaliate from this role. As a result, this can create incongruence between 'who the person wants to be' and 'who other people want them to be' leading to serious psychological problems for the individual. It is therefore possible that just like the youngest child from the ordinal birth order; the pressures associated with the 
psychological first can lead to birth order related irrational thoughts leading to maladaptive coping strategies and possibly lead to addiction amongst other mental health issues. More evidence to support this comes from (Batte, 1996) who believe that "irrational thoughts breed negative intrapersonal speech which do not foster growth but rather have negative consequences on the person” (p.5).

Clinicians in the area of addiction can use the present study to further generate hypothesis about the role of ordinal and psychological birth order when it comes to the development of substance related disorders. One application of the present study is that clinicians can incorporate birth order sensitive strategies into their treatment plans. Another way of incorporating the findings of the present study in treatment is by counteracting the effect of being 'an only'. The present study has also generated sufficient evidence indicating that birth order is not only a western phenomenon since it also has a place in the Kenyan population.

Another implication of the study goes to parenting and especially how parents treat children on ground of birth order or on whatever basis. By making this information explicit to current or future parents, they invest time in thinking about how birth order related attitudes towards children can significantly cause psychological problems in the child's future. The results of this study can also be incorporated in parenting classes as a way of also improving how parents relate to their children for the better.

Limitations of the study entailed the use of male participants and, the use of a case study from only one rehabilitation centre which should be avoided in future replications. 
It is also astonishing that none of the participants rated themselves as psychological youngest. Future research should therefore replicate this study and also extend it by incorporating both sexes and a larger sample as opposed to conducting a case study from one rehabilitation centre.

All in all, the results illustrate that indeed birth order does play a role when it comes to addiction. It is therefore essential for future research to replicate this area in research in order to further understand the nature of psychological birth order and how it transpires to the development of addiction. Since the study generated contradictory results between the ordinal and the psychological birth order, this may suggest that the two variables are in deed distinctively different. It therefore seems that different factors may be at play in both ordinal and psychological birth order and hence, the need for more research to bridge the gap between these two variables if clinicians are to offer birth order sensitive treatment to their patients and clients.

\section{REFERENCES}

Adler, A. (1931). Cited in Corey, G. (2009). Theory and Practice of Counseling and Psychotherapy. $8^{\text {th }}$ ed. CA: Thomson Brooks/Cole.

Adler, A. (2005). Cited in Kalkan, M. (2008). The Relationship of Psychological Birth Order to Irrational Relationship Beliefs. Social Behaviour and Personality, 36(4), 455-466. Retrieved on 13/02/2010 from Ebscohost Database.

Ashby, J. S., LoCicero, K. A., \& Kenny, M. C. (2003). The Relationship of Multidimensional Perfectionism to Psychological Birth Order. Journal of 
Individual Psychology, 59 (1), 42-51. Retrieved on 4/08/2010 from University of Texas Database.

Batte, M. (1996). Cited in Mukangi, A. (2010). Rational Emotive Behavioural Therapy (REBT): A critical review. The Journal of Language, Technology \& Entrepreneurship in Africa, 2 (1), 54 - 65. Retrieved on 18/08/2010 from AJOL Database.

Craighead, W. E., \& Nameroff, C. B. (2002). The Corsini Encyclopedia of Psychology and Behavioural Science. 3rd ed. NY: John Wiley \& Sons Publishers. Retrieved on 14/08/2010 from Google Books Database.

Doweiko, H. E. (2008). Concepts of Chemical Dependency. CA: Brooks/Cole Publishers. Retrieved on 14/08/2010 from Google Books Database.

Dunbar, R. I. M., \& Barrett, L. (2007). Oxford Handbook of Evolutionary Psychology. NY: Oxford University Press. Retrieved on 14/08/2010 from Google Books Database.

Fiske, S. T., Gilbert, D. T., \& Lindzey, G. (2010). Handbook of Social Psychology, $5^{\text {th }}$ ed. Volume Two. NJ: John Wiley \& Sons. Retrieved on 25/07/2010 from Google Books Database.

Hartshorne, J. K., Salem-Hartshorne, N., \& Hartshorne, T. S. (2009). Birth Order Effects in the Formation of Long-Term Relationships. Journal of Individual Psychology, 65 (2), 156-176. Retrieved on 13/02/2010 from Ebscohost Database.

Gfroerer, K. P., Gfroerer, C. A., Curlette, W. L., White, J., \& Kern, R. M. (2003). Cited in Cited in Kalkan, M. (2008). The Relationship of Psychological Birth Order to Irrational Relationship Beliefs. Social Behaviour and Personality, 36(4), 455-466. 
Retrieved on 13/02/2010 from Ebscohost Database.

Kalkan, M. (2008). The Relationship of Psychological Birth Order to Irrational Relationship Beliefs. Social Behaviour and Personality, 36(4), 455-466. Retrieved on 13/02/2010 from Ebscohost Database.

Lerner, S. E., \& Linder, R. L. (1975). Birth Order and Polydrug Abuse among Heroin Addicts. Journal of Drug Education, 5, (3), 285-290. Retrieved on 25/07/2010 from ERIC Database.

Philips, A. S., \& Philips, C. R. (1994). Cited in Kalkan, M. (2008). The Relationship of Psychological Birth Order to Irrational Relationship Beliefs. Social Behaviour and Personality, 36(4), 455-466. Retrieved on 13/02/2010 from Ebscohost Database.

Rickert, L. (2002). Birth order and its effects on personality. Retrieved on 25/07/2010 from www.essortment.com.

Schachter, S. (1959). Cited in Smart, R. G. (1963). Alcoholism, birth order, and family size. Journal of Abnormal and Social Psychology, 66 (1), 17-23. Retrieved on 25/07/2010 from Science Direct Database.

Sharf, R. (2008). Theories of Psychotherapy and Counseling: Concepts and Cases. $4^{\text {th }}$ ed. CA: Wadsworth Publishers.

Sigelman, C. K., \& Rider, E. A. (2008). Life-Span Human Development. $6^{\text {th }}$ ed. CA: Wadsworth Cengage Learning. Retrieved on 15/08/2010 from Google Books Database.

Smart, R. G. (1963). Alcoholism, birth order, and family size. Journal of Abnormal and Social Psychology, 66 (1), 17-23. Retrieved on 25/07/2010 from Science Direct 
Database.

Stagner, B. H. (1986). Viability of Birth Order studies in Substance Abuse Research, Substance Use \& Misuse, 21, (3), 377 - 384. Retrieved on 25/07/2010 from Informa world Database

Stewart, A. E. (2004). Cited in Kalkan, M. (2008). The Relationship of Psychological Birth Order to Irrational Relationship Beliefs. Social Behaviour and Personality, 36(4), 455-466. Retrieved on 13/02/2010 from Ebscohost Database.

Stewart, A. E., \& Campbell, L. F. (1998). Cited in Kalkan, M. (2008). The Relationship of Psychological Birth Order to Irrational Relationship Beliefs. Social Behaviour and Personality, 36(4), 455-466. Retrieved on 13/02/2010 from Ebscohost Database.

Sutherland, E. H., Cressey, D. R., \& Luckenbill, D. F. (1992). Principles of Criminology. $11^{\text {th }}$ ed. NY: General Hall Publishers. Retrieved on 14/08/2010 from Google Books Database.

Sullivan, B. F., \& Schwebel, A. (1996). Cited in Kalkan, M. (2008). The Relationship of Psychological Birth Order to Irrational Relationship Beliefs. Social Behaviour and Personality, 36(4), 455-466. Retrieved on 13/02/2010 from Ebscohost Database.

Stewart, A. E., \& Campbell, L. F. (1998). Cited in Cited in Kalkan, M. (2008). The Relationship of Psychological Birth Order to Irrational Relationship Beliefs. Social Behaviour and Personality, 36(4), 455-466. Retrieved on 13/02/2010 from Ebscohost Database.

Weeks, K. G., \& Newlon, B. J. (1984). Birth Order and Perceived Birth Order of 
Chemically Dependent and Academic Women. Retrieved on 25/07/2010 from ERIC Database.

Weller, W. (1962). The Relationship of Birth Order to Anxiety: A Replication of the Schachter Findings. Sociometry, 25 (4), 415-417. Retrieved on 25/07/2010 from JSTOR Database.

White, J., Campbell, L., \& Stewart, A. (1991). Cited in Cited in Kalkan, M. (2008). The Relationship of Psychological Birth Order to Irrational Relationship Beliefs. Social Behaviour and Personality, 36(4), 455-466. Retrieved on 13/02/2010 from Ebscohost Database.

Zajonc, R. B., \& Mullally, P. R. (1997). Cited in Kalkan, M. (2008). The Relationship of Psychological Birth Order to Irrational Relationship Beliefs. Social Behaviour and Personality, 36(4), 455-466. Retrieved on 13/02/2010 from Ebscohost Database.

Zajonc, R. B. (2001). Cited in Kalkan, M. (2008). The Relationship of Psychological Birth Order to Irrational Relationship Beliefs. Social Behaviour and Personality, 36(4), 455-466. Retrieved on 13/02/2010 from Ebscohost Database. 